\title{
Front Matter: Volume 11454
}

, "Front Matter: Volume 11454," Proc. SPIE 11454, X-Ray, Optical, and Infrared Detectors for Astronomy IX, 1145401 (7 January 2021); doi: $10.1117 / 12.2591721$

SPIE. Event: SPIE Astronomical Telescopes + Instrumentation, 2020, Online Only 


\title{
PROCEEDINGS OF SPIE
}

\section{$X-R a y$, Optical, and Infrared Detectors for Astronomy IX}

\author{
Andrew D. Holland \\ James Beletic \\ Editors
}

14-22 December 2020

Online Only, United States

Sponsored and Published by

SPIE 
The papers in this volume were part of the technical conference cited on the cover and title page. Papers were selected and subject to review by the editors and conference program committee. Some conference presentations may not be available for publication. Additional papers and presentation recordings may be available online in the SPIE Digital Library at SPIEDigitalLibrary.org.

The papers reflect the work and thoughts of the authors and are published herein as submitted. The publisher is not responsible for the validity of the information or for any outcomes resulting from reliance thereon.

Please use the following format to cite material from these proceedings:

Author(s), "Title of Paper," in X-Ray, Optical, and Infrared Detectors for Astronomy IX, edited by Andrew D. Holland, James Beletic, Proceedings of SPIE Vol. 11454 (SPIE, Bellingham, WA, 2020) Seven-digit Article CID Number.

ISSN: 0277-786X

ISSN: 1996-756X (electronic)

ISBN: 9781510636958

ISBN: 9781510636965 (electronic)

Published by

SPIE

P.O. Box 10, Bellingham, Washington 98227-0010 USA

Telephone +1 3606763290 (Pacific Time) · Fax +1 3606471445

SPIE.org

Copyright (c) 2020, Society of Photo-Optical Instrumentation Engineers.

Copying of material in this book for internal or personal use, or for the internal or personal use of specific clients, beyond the fair use provisions granted by the U.S. Copyright Law is authorized by SPIE subject to payment of copying fees. The Transactional Reporting Service base fee for this volume is $\$ 21.00$ per article (or portion thereof), which should be paid directly to the Copyright Clearance Center (CCC), 222 Rosewood Drive, Danvers, MA 01923. Payment may also be made electronically through CCC Online at copyright.com. Other copying for republication, resale, advertising or promotion, or any form of systematic or multiple reproduction of any material in this book is prohibited except with permission in writing from the publisher. The CCC fee code is $0277-$ $786 \times / 20 / \$ 21.00$.

Printed in the United States of America by Curran Associates, Inc., under license from SPIE.

Publication of record for individual papers is online in the SPIE Digital Library.

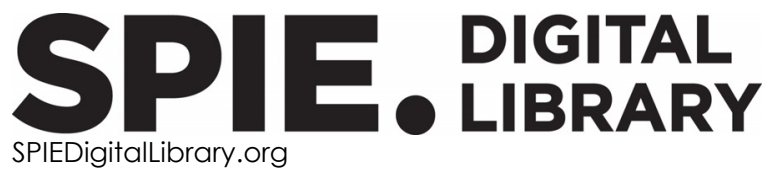

Paper Numbering: Proceedings of SPIE follow an e-First publication model. A unique citation identifier (CID) number is assigned to each article at the time of publication. Utilization of CIDs allows articles to be fully citable as soon as they are published online, and connects the same identifier to all online and print versions of the publication. SPIE uses a seven-digit CID article numbering system structured as follows:

- The first five digits correspond to the SPIE volume number.

- The last two digits indicate publication order within the volume using a Base 36 numbering system employing both numerals and letters. These two-number sets start with $00,01,02,03,04$, 05, 06, 07, 08, 09, 0A, OB ... 0Z, followed by 10-1Z, 20-2Z, etc. The CID Number appears on each page of the manuscript. 


\section{Contents}

INDUSTRY INTRODUCTORY PRESENTATIONS

1145402 Enhanced silicon sensor capabilities at Teledyne e2v (Invited Paper) [1 1454-1]

\section{CAMERAS AND SIMULATION}

1145407 Design of a large-format high-rate scientific CMOS camera [11454-7]

1145408 Pyxel: the collaborative detection simulation framework [1 1454-8]

RADIATION DAMAGE I

1145409 Comparison of proton and electron radiation effects on dark count rate in a CMOS SPAD sensor [11454-9]

11454 OA Impact of proton radiation on the Ariel AIRS CH1 HAWAll-1RG MWIR detector [11454-10]

11454 OB A study of the silicon divacancy defect in the E2V LSST CCD250 using the single trap pumping method [11454-11]

\section{CMOS FOR VISIBLE}

11454 OE Quantum efficiency of the CIS115 in a radiation environment [1 1454-14]

11454 OF Mitigating charge spill-back induced image lag with a multi-level transfer gate pulse in PPD image sensors [11454-15]

11454 OG Evaluation of scientific CMOS sensors for sky survey applications [11454-17]

\section{X-RAY SENSORS I}

11454 Ol Development of a photon-counting near-fano-limited x-ray CMOS image sensor for THESEUS' SXI [11454-19]

11454 OK Developing the detector of X-ray imaging spectrometer for GEO-X mission [1 1454-21] 


\section{RADIATION DAMAGE II}

1145400 Experimental study of the influence of the CdZnTe substrate thickness on the response of infrared HgCdTe photodetectors under proton irradiation [1 1454-25]

11454 OP Proton radiation hardness of x-ray SOI pixel detectors with pinned depleted diode structure [1 1454-26]

$114540 Q \quad$ Radiation damage testing status of the CCDs for the SMILE SXI [1 1454-27]

11454 OS Gaia CCDs: charge transfer inefficiency measurements between five years of flight [1 1454-29]

\section{X-RAY SENSORS II}

11454 OT Processing x-ray data on board the SMILE SXI [1 1454-30]

11454 OU Advanced DePFET concepts: super gq DePFET [11454-31]

\section{CRYOGENIC DETECTORS}

1145412 Development of microwave multiplexer for the Super DIOS mission: 38 transition-edge sensor $\mathrm{x}$-ray microcalorimeter readout with microwave multiplexing [1 1454-40]

1145414 First operation of transition-edge sensors in space with the Micro-X sounding rocket [1 1454-44]

TEST RESULTS

1145418 Development of an optical photon counting imager using a monolithic Geiger APD array [1 1454-49]

\section{CCDS I}

$114541 \mathrm{~A} \quad$ Characterization of skipper CCDs for cosmological applications [11454-51]

$114541 \mathrm{~B} \quad$ Germanium charge-coupled devices for hard x-ray astronomy [1 1454-52]

iv 
CCDS II

$114541 C$ Charge transfer effects in a CCD with a single polysilicon gate structure [1 1454-53]

11454 1D Design of a front-illuminated scientific CCD camera for space debris observation [1 1454-55]

$11454 \mathrm{IF}$ Developing the active trap model for CCD charge transfer optimisation in large-scale space missions [11454-57]

\section{QE IMPROVEMENT}

11454 IG Calibrating Teledyne-e2v's ultraviolet image sensor quantum efficiency processes [1 1454-58]

$11454 \mathrm{1H} \quad$ Development of UV imaging detectors with atomic layer deposited microchannel plates and cross strip readouts [11454-60]

INFRA RED DETECTORS II

$114541 \mathrm{~K}$ Persistence and dark current characterization on HgCdTe short wave infrared imagers for astronomy at CEA and Lynred [1 1454-64]

11454 1N Characterisation, performance, and operational aspects of the H4RG-15 near infrared detectors for the MOONS instrument [1 1454-67]

11454 IP Characterization of the optical properties of the buried contact of the JWST MIRI Si: as infrared blocked impurity band detectors [11454-69]

POST-DEADLINE

$114541 \mathrm{X} \quad \mathrm{X}$-ray analysis of the EMCCD point-source response [11454-147]

POSTER SESSION

$114541 \mathrm{Y}$ Detector systems engineering for extremely large instruments [11454-71]

1145412 The simulation framework of the timing-based localization for future all-sky gamma-ray observations with a fleet of CubeSats [1 1454-73]

1145420 Design of second version driver and readout ASICs for scientific CCD detectors [11454-74]

1145422 Characterization of a high efficiency silicon photomultiplier for millisecond to sub-microsecond astrophysical transient searches [11454-79] 
1145423 Tiny-box: a tool for the versatile development and characterization of low noise fast x-ray imaging detectors [1 1454-80]

1145425 Detection systems for high time resolution astrophysics: based on advances in lidar technologies [11454-83]

1145426 A smartphone-based arbitrary scene projector for detector testing and instrument performance evaluation [11454-84]

1145427 MCRC V1: development of integrated readout electronics for next generation x-ray CCD detectors for future satellite observatories [1 1454-85]

$1145428 \quad$ LWIR quantum efficiency measurements using a calibrated MCT photodiode read by a cryoHEMT-based amplifier [1 1454-86]

$114542 \mathrm{C} \quad$ Initial assessment of monocrystalline silicon solar cells as large-area sensors for precise flux calibration [1 1454-90]

$114542 \mathrm{D} \quad$ Surface features in U-band of ITL devices for the LSST telescope [1 1454-91]

$114542 \mathrm{E} \quad$ Remote monitor and control implementation via an optical digital link [1 1454-92]

$114542 \mathrm{G}$ Suitability of COTS InGaAs detectors for ground-based exoplanet detections around nearby M-dwarfs [1 1454-94]

11454 2J PANIC-4K: upgrade with a HAWAll-4RG array [1 1454-99]

$114542 \mathrm{M} \quad$ Monte Carlo simulations of hyper-velocity particulate mechanics within silicon micropore optics [1 1454-102]

$114542 \mathrm{~N} \quad$ First proton and gamma radiation of the MCT NIR European astronomy large format array detector [11454-104]

1145420 Detector architecture of the wide-field infrared transient explorer (WINTER) InGaAs camera [11454-105]

$114542 \mathrm{P} \quad$ The characteristic of Teledyne e2v CIS 113 CMOS sensors [1 1454-106]

$114542 S$ Study on possible proton-induced background of $\operatorname{LaBr}_{3}(\mathrm{Ce})$ scintillator in a low-Earth orbit [1 1454-109]

$114542 \mathrm{~T} \quad$ Design of an extended area blackbody for calibration of near infrared sky brightness monitor in the Antarctic [1 $1454-110]$

$114542 U$ Design of the electronic system for a $2 \times 2$ mosaic CCD camera [1 1454-111]

$114542 \mathrm{~V}$ On-the-fly data pipeline for image processing enabling real-time persistence correction [1 1454-112] 
$114542 Y \quad$ Design of a test platform for scientific CMOS cameras [1 1454-115]

$114542 Z$ Multiplexable frequency retuning of MKID arrays using their non-linear kinetic inductance [1 1454-116]

1145430 Optimization of a CCD-in-CMOS TDI detector's operating clock voltages by Taguchi based Grey relational analysis [11454-117]

$1145431 \quad$ ROIC glow reduction in very low flux short wave infra-red focal plane arrays for astronomy [11454-118]

1145432 Classification of bad pixels of the Hawaii-2RG detector of the ASTROnomical NearlnfraRed CAMera [1 1454-119]

1145435 Signal nonlinearity measurements and corrections in MWIR and LWIR HgCdTe H2RG arrays for NEO Surveyor [1 1454-123]

1145437 Instrument development with infrared APD arrays [1 1454-125]

$1145438 \quad X$-ray photon counting performance of front-illuminated scientific CMOS image sensor [11454-126]

1145439 Laboratory measurements of instrumental signatures of the LSST camera focal plane [1 1454-127]

11454 3C Panoramic SETI: on-sky results from prototype telescopes and instrumental design [11454-130]

11454 3E Measuring the impact of CCD gate width on the brighter-fatter effect [1 1454-132]

11454 3J Performance advantages of buffered mode operation of HxRG near infrared detectors [1 1454-138]

11454 3L Design of a test platform with a cyrocooler for InGaAs FPA [11454-141] 
Proc. of SPIE Vol. 11454 1145401-8

Downloaded From: https://www.spiedigitallibrary.org/conference-proceedings-of-spie on 26 Apr 2023 Terms of Use: https://www.spiedigitallibrary.org/terms-of-use 